\title{
Theoretical Studies of the Electric Field Gradient in Hexachlorometallates
}

\author{
Dirk Borchers*, Peter C. Schmidt, and Alarich Weiss \\ Institut für Physikalische Chemie, Physikalische Chemie III, Technische Hochschule Darmstadt, \\ Darmstadt, West Germany
}

Z. Naturforsch. 43a, 643-650 (1988); received April 16, 1988

The electric field gradient (EFG) at the chlorine site is calculated for cubic compounds of the $\mathrm{K}_{2} \mathrm{PtCl}_{6}$-type (space group $\mathrm{Fm} 3 \mathrm{~m}$ ), $\mathrm{M}_{2}^{\mathrm{I}} \mathrm{M}^{\mathrm{IV}} \mathrm{Cl}_{6}$, where $\mathrm{M}^{\mathrm{I}}$ is an alkali metal and $\mathrm{Me}^{\mathrm{IV}}$ a tetravalent element. In the calculations the total EFG is subdivided into the contribution of the complex $\left[\mathrm{M}^{\mathrm{IV}} \mathrm{Cl}_{6}\right]^{2-}, \mathrm{EFG}_{\text {complex }}$, and the contribution of the ions outside the complex, EFG $\mathrm{F}_{\text {lattice }} . \mathrm{EFG}_{\text {complex }}$ is calculated by the local electron density formalism using the MS-X $\alpha$-method, and $E_{\text {lattice }}$ is determined by the point charge model.

It is found that $\mathrm{EFG}_{\text {complex }}$ is positive whereas $\mathrm{EFG}_{\text {lattice }}$ is negative. Including antishielding effects, the magnitude of $\mathrm{EFG}_{\text {lattice }}$ is about one fourth of EFG $\mathrm{EFmpl}_{\text {com }}$. The trends in the EFG for the various compounds found theoretically are the same as the trends in the experimental nuclear quadrupole coupling constants $e^{2} Q q / h$. However, the absolute values of $\mathrm{EFG}_{\text {theo }}$ are smaller than the values $\mathrm{EFG}_{\exp }$ deduced from $e^{2} Q q / h$.

For a fixed central atom $\mathbf{M}^{\mathrm{IV}}$ the (positive) $\mathrm{EFG}_{\text {exp. }}$ is increasing with increasing radii of the cations (and increasing lattice constant). This increase can be understood by an increase of $\mathrm{EFG}_{\text {lattice }}$.

On the other hand, for fixed cations and different tetravalent metal atoms, the EFG is increasing with increasing electronegativity of the central atom. This can be understood by an increase of $\mathrm{EFG}_{\text {complex }}$. For distorted octahedra it is found that the change in the EFG due to the distortion is also due to a change in $\mathrm{EFG}_{\text {complex }}$.

\section{Introduction}

In the past 30 years many hexachlorometallates with composition $\mathrm{M}_{2}^{\mathrm{I}} \mathrm{M}^{\mathrm{IV}} \mathrm{Cl}_{6}$, where $\mathrm{M}^{\mathrm{I}}$ is an alkali metal or organic cation and $\mathrm{M}^{\mathrm{IV}}$ is a tetravalent element, have been studied by ${ }^{35} \mathrm{Cl}$ nuclear quadrupole resonance (NQR) spectroscopy; for a review of the experimental data see $[1,2]$. Experimental NQR-data for hexabromo- and hexaiodometallates are more scarce. Hexahalometallates for which $\mathrm{M}^{\mathrm{I}}$ is an alkali metal ion crystallize in large majority in the highly symmetric structure of the $\mathrm{K}_{2} \mathrm{PtCl}_{6}$-type (space group $\left.\mathrm{O}_{\mathrm{h}}^{5}-\mathrm{Fm} 3 \mathrm{~m}\right)$. Since the point symmetry of the halogen atoms within the $\mathrm{K}_{2} \mathrm{PtCl}_{6}$-type is $4 \mathrm{~mm}$, the asymmetry parameter $\eta$ is zero and $2 v$ (Halogen) $=e^{2} Q q / h$ (Halogen), the nuclear quadrupole coupling constant (NQCC). The values for the measured ${ }^{35} \mathrm{Cl} \mathrm{NQR}$ frequencies of $\mathrm{M}_{2}^{\mathrm{I}} \mathrm{M}^{\mathrm{IV}} \mathrm{Cl}_{6}$ are within the range of 9 to $28 \mathrm{MHz}[1,2]$. As the ${ }^{35} \mathrm{Cl} \mathrm{NQR} \mathrm{fre-}$

\footnotetext{
* Part of Dr.-Ing. thesis of Dirk Borchers, Technische Hochschule Darmstadt, D17.

Reprint requests to Prof. Dr. Al. Weiss, Institut für Physikalische Chemie, Technische Hochschule Darmstadt, Petersenstraße 20, D-6100 Darmstadt.
}

quencies in the hexachlorometallates are distinctly smaller than those in purely covalent chlorine compounds and distinctly larger than those in pure ionic environments $[3,4]$ one expects a complicated interplay of covalent and ionic contributions to the electric field gradient $(\mathrm{EFG})$ at the chlorine site $\left(e q\left({ }^{35} \mathrm{Cl}\right)\right)$ in these compounds. Therefore a pure ionic model fails in describing the magnitude and trends in the NQR data [5]. To interpretate the measured EFG it is necessary to study covalent as well as ionic contributions to the EFG.

In the present work we have calculated the various contributions to the EFG by the following procedure. The crystal is separated into two regions, the region of the complex $\left[\mathrm{M}^{\mathrm{IV}} \mathrm{Cl}_{6}\right]^{2-}$ which includes the nucleus considered and the rest of the lattice. The EFG produced by the complex is investigated by a molecular ab initio self consistent field (SCF) calculation [6] within the local density formalism [7] using the multiple scattering $\mathrm{X} \alpha$-method (MS-X $\alpha$ ) $[8,9]$. The contribution to the EFG due to the rest of the lattice is handled by the point charge model [10]. It is expected that this computational treatment is quite reasonable. The arguments are the following: For compounds $\mathrm{M}_{2}^{\mathrm{I}}\left[\mathrm{M}^{\mathrm{IV}} \mathrm{Cl}_{6}\right]$, for which $\mathrm{M}^{\mathrm{I}}$ is an alkali atom, covalent 
bonds and overlap charge densities should mainly exist within the complexes $\left[\mathrm{M}^{\mathrm{IV}} \mathrm{Cl}_{6}\right]^{2-}$. There is only a negligible charge overlap between these anions and the cations. Therefore the interaction between the cation and the anion sublattices is predominately ionic and the point charge model can be successfully used to study the EFG produced by the charges external to the complex [11].

For those compounds for which the cations are partially substituted ammonium ions the situation is much more complicated. First of all the lower symmetry of these compounds [12] will lead to a decrease of crystal symmetry and the $\mathrm{X} \alpha$-method should be less suitable (see below). Furthermore, the occurence of hydrogen bonds $\mathrm{N}-\mathrm{H} \ldots \mathrm{Cl}$ will give an additional covalent interaction between the cation and the anion sublattices bridged by hydrogen bonds.

\section{Methods}

Within the principal axis system the $z$ component of the electric field gradient $e q$ is given by

$$
e q=\int_{\Omega} \frac{\varrho(r)\left(3 \cos ^{2} \vartheta-1\right)}{r^{3}} \mathrm{~d} \tau
$$

where $\varrho(r)$ is the sum of the charge density of the electrons, $\varrho_{\mathrm{e}}(r)$, and the charge density of the nuclei, $\varrho_{\mathrm{N}}(r) . \vartheta$ is the angle between the line joining the charged volume element $\mathrm{d} \tau$ to the central nucleus considered $(\mathrm{Cl})$ and the $z$-axis $(z=r \cdot \cos \vartheta)$.

$$
\varrho_{\mathrm{N}}(r)=\sum_{i} Z_{i} e \delta\left(r-r_{i}\right) \text {. }
$$

$r_{i}$ are the positions of the nuclei with respect to the choosen origin in the crystal lattice, which is the $\mathrm{Cl}$ nulceus considered. $\Omega$ is the crystal volume.

As mentioned in the Introduction, the integral (1) over $\Omega$ is seperated into an integration over the $\left[\mathrm{M}^{\mathrm{IV}} \mathrm{Cl}_{6}\right]^{2-}$ complex (volume $\Omega_{\mathrm{C}}$ )

$$
e q_{\text {complex }}=\int_{\Omega_{\mathrm{C}}} \frac{\varrho(r)\left(3 \cos ^{2} \vartheta-1\right)}{r^{3}} \mathrm{~d} \tau
$$

and an integration over the rest $\Omega^{\prime}$.

This latter contribution is called $e q_{\text {lattice}}$, it is approximated by the point charge model:

$$
e q_{\text {lattice }}=\sum_{i} Z_{i}^{\prime} e \frac{\left(3 \cos ^{2} \vartheta-1\right)}{r^{3}},
$$

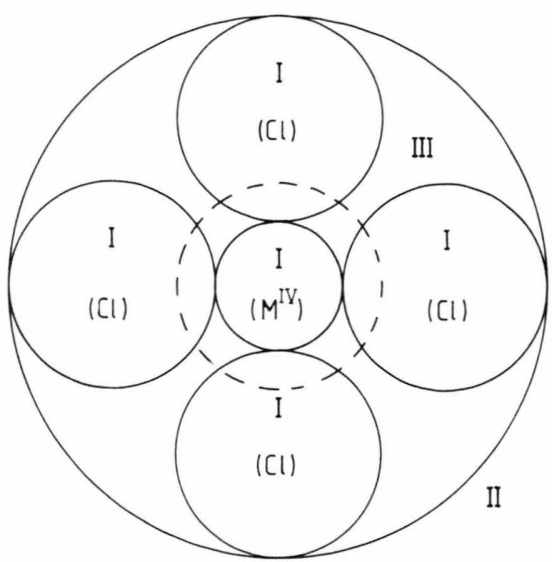

Fig 1. Different regions for the $\mathrm{X} \alpha$-SCF calculations, plane $z=0$. Regions I are atomic muffin-tin spheres, II is the region outside the outersphere and III is the intersphere region. The dotted line shows the muffin-tin spheres of the chlorine atoms above and below the $z=0$ plane.

where $Z_{i}^{\prime}$ are the atomic point charges, which are equal to +1 for the cations and which are partial charges deduced from the molecular SCF calculation for the atoms of the complex, see below. The summation in (4) has to be taken over all atomic charges of $\Omega^{\prime}$.

The EFG contribution of the complex is determined from the electron wave functions, which are calculated by the $\mathrm{X} \alpha$-method [7,8] using the exchange parameters given by Schwarz [13]. To calculate the potential seen by the electrons, $\Omega_{\mathrm{C}}$ is separated into three regions (muffin-tin approximation), see Figure 1. Regions I are non overlapping or slightly overlapping spheres around the nuclei, region II is the volume outside an outer sphere around the atomic spheres and region III is the rest of $\Omega_{\mathrm{C}}$. In the regions I and II the potential is in approximation spherical symmetric, and in region III the potential is assumed to be constant. The partial charges $Z_{i}^{\prime}$ used in the lattice sum (4) are the charges inside the muffin-tin spheres plus the charge of regions II and III distributed over the spheres.

The total EFG is not just the sum $e q_{\text {complex }}+e q_{\text {lattice }}$ as the influence of the lattice (the charges of $\Omega^{\prime}$ ) on the charges of the complex is not taken into account. Approximately the interaction between the complex and the lattice is considered in the following way.

The crystal field effect on the energy levels and charges of the complex is partly taken into consideration by an outer potential produced by a charged 
Table 1. Geometrical arrangement of the atoms in the $\left[\mathrm{M}^{\mathrm{IV}} \mathrm{Cl}_{6}\right]$ complex.

Regular octahedra: $\mathrm{M}^{\mathrm{IV}}$ on $(0,0,0) ; \mathrm{Cl}$ on $(x, 0,0) ;(\bar{x}, 0,0) ;(0, x, 0) ;(0, \bar{x}, 0) ;(0,0, x) ;(0,0, \bar{x})$.

Tetragonal distorted octahedron: $\mathbf{M}^{\mathrm{IV}}$ on $(0,0,0) ; \mathrm{Cl} 1$ on $(x, 0,0) ;(\bar{x}, 0,0) ;(0, x, 0) ;(0, \bar{x}, 0) ; \mathrm{Cl} 2$ on $(0,0, z) ;(0,0, \bar{z})$.

\begin{tabular}{|c|c|c|c|c|c|c|c|c|}
\hline & \multirow[t]{2}{*}{ Overlap } & \multicolumn{6}{|c|}{ Sphere radii $[\AA]$} & \multirow[t]{2}{*}{ Lit. } \\
\hline & & $R(\mathrm{Cl})$ & $R\left(\mathrm{M}^{\mathrm{IV}}\right)$ & $R(\mathrm{OUT})$ & $R$ (Watson) & $x(z)$ & $\begin{array}{l}\text { lattice } \\
\text { constant }\end{array}$ & \\
\hline $\mathrm{Cs}_{2} \mathrm{GeCl}_{6}$ & $\begin{array}{l}0 \% \\
5 \%\end{array}$ & $\begin{array}{l}1.218 \\
1.275\end{array}$ & $\begin{array}{l}1.131 \\
1.184\end{array}$ & $\begin{array}{l}3.568 \\
3.625\end{array}$ & $\begin{array}{l}3.568 \\
3.625\end{array}$ & $\begin{array}{l}2.35 \\
2.35\end{array}$ & $\begin{array}{l}10.23 \\
10.23\end{array}$ & {$[18]$} \\
\hline $\mathrm{K}_{2} \mathrm{SnCl}_{6}$ & $\begin{array}{l}0 \% \\
5 \%\end{array}$ & $\begin{array}{l}1.218 \\
1.275\end{array}$ & $\begin{array}{l}1.200 \\
1.260\end{array}$ & $\begin{array}{l}3.638 \\
3.694\end{array}$ & $\begin{array}{l}3.694 \\
3.694\end{array}$ & $\begin{array}{l}2.42 \\
2.42\end{array}$ & $\begin{array}{l}9.982 \\
9.982\end{array}$ & [19] \\
\hline $\mathrm{Cs}_{2} \mathrm{SnCl}_{6}$ & $\begin{array}{l}0 \% \\
5 \%\end{array}$ & $\begin{array}{l}1.218 \\
1.275\end{array}$ & $\begin{array}{l}1.200 \\
1.260\end{array}$ & $\begin{array}{l}3.638 \\
3.694\end{array}$ & $\begin{array}{l}3.710 \\
3.710\end{array}$ & $\begin{array}{l}2.42 \\
2.42\end{array}$ & $\begin{array}{l}10.355 \\
10.355\end{array}$ & {$[19]$} \\
\hline $\mathrm{Cs}_{2} \mathrm{PbCl}_{6}$ & $\begin{array}{l}0 \% \\
5 \%\end{array}$ & $\begin{array}{l}1.218 \\
1.275\end{array}$ & $\begin{array}{l}1.323 \\
1.385\end{array}$ & $\begin{array}{l}3.758 \\
3.816\end{array}$ & $\begin{array}{l}3.852 \\
3.816\end{array}$ & $\begin{array}{l}2.54 \\
2.54\end{array}$ & $\begin{array}{l}10.415 \\
10.415\end{array}$ & {$[20]$} \\
\hline $\mathrm{Cs}_{2} \mathrm{TeCl}_{6}$ & $\begin{array}{l}0 \% \\
5 \%\end{array}$ & $\begin{array}{l}1.218 \\
1.275\end{array}$ & $\begin{array}{l}1.295 \\
1.356\end{array}$ & $\begin{array}{l}3.728 \\
3.760\end{array}$ & $\begin{array}{l}3.736 \\
3.760\end{array}$ & $\begin{array}{l}2.51 \\
2.51\end{array}$ & $\begin{array}{l}10.466 \\
10.466\end{array}$ & [20] \\
\hline $\mathrm{Rb}_{2} \mathrm{TiCl}_{6}$ & $\begin{array}{l}0 \% \\
5 \%\end{array}$ & $\begin{array}{l}1.218 \\
1.275\end{array}$ & $\begin{array}{l}1.122 \\
1.175\end{array}$ & $\begin{array}{l}3.558 \\
3.614\end{array}$ & $\begin{array}{l}3.558 \\
3.614\end{array}$ & $\begin{array}{l}2.34 \\
2.34\end{array}$ & $\begin{array}{l}9.942 \\
9.942\end{array}$ & {$[20]$} \\
\hline $\begin{array}{l}\text { tetragonal } \\
\text { distorted } \\
\text { octahedron }\end{array}$ & $0 \%$ & 1.218 & 1.200 & 3.679 & 3.704 & $\begin{array}{l}2.42(\mathrm{Cl} 1) \\
2.46(\mathrm{Cl} 2)\end{array}$ & & \\
\hline
\end{tabular}

sphere around the complex centered at the $\mathrm{M}^{\mathrm{IV}}$ nucleus (Watson-sphere model) $[14,15]$. The charge of the Watson-sphere is equal to +2 , and the radius of the Watson sphere is chosen in such a way that the potential inside the sphere is equal to the Madelung potential of the lattice (excluding the charges of the complex). Of course, this Watson-sphere potential does not take into account the non spherical part of the crystal potential causing a shielding effect on the EFG.

The shielding is considered by the Sternheimer procedure [16]:

$$
e q_{\text {shielding }}=-\gamma_{\infty} \cdot e q_{\text {lattice }},
$$

where $\gamma_{\infty}$ is the antishielding factor.

We have used $\gamma_{\infty}=\gamma_{\infty}(\mathrm{Cl})_{3 p}=-42$, which is calculated for $\mathrm{Cl}^{-}$in a crystal environment [17]. The antishielding effect of the $2 p$ shell is much smaller $\left(\gamma_{\infty}(\mathrm{Cl})_{2 \mathrm{p}}=-0.737\right)$, and it is found that the contribution of the shielding of the $2 \mathrm{p}$ shell can be neglected.

According to this model the total EFG is separated into the following contributions:

The contribution of the chlorine atom centered at the position of the nucleus considered:

$$
e q_{\text {local }}=\int_{\Omega_{\mathrm{Cl}}} \frac{\varrho(r)\left(3 \cos ^{2} \vartheta-1\right)}{r^{3}} .
$$

$e q_{\text {local }}$ is calculated by integrating over the $\mathrm{Cl}$ atomic sphere of volume $\Omega_{\mathrm{Cl}}$.

The contribution of the rest of the complex:

$$
e q_{\text {distant }}=\int_{\Omega_{\mathrm{C}} \neq \Omega_{\mathrm{C} 1}} \frac{\varrho(r)\left(3 \cos ^{2} \vartheta-1\right)}{r^{3}} .
$$

$e q_{\text {distant }}$ is the contribution of the cores of the atoms in the complex and of the charge density of the valence electron outside $\Omega_{\mathrm{Cl}}$.

The total contribution of the whole complex is given by

$$
e q_{\text {complex }}=e q_{\text {local }}+e q_{\text {distant }} .
$$

For the contribution of the lattice $e q_{\text {lattice }}$, see (4).

Then the total EFG is given by

$$
e q_{\text {total }}=e q_{\text {local }}+e q_{\text {distant }}+\left[1-\gamma_{\infty}\right] \cdot e q_{\text {lattice }} .
$$

In the next section these contributions to $e q_{\text {total }}$ are given for the systems studied here.

\section{Results}

The parameters used for the $\mathrm{X} \alpha$-cluster calculations and the evaluation of the lattice sums are listed in Table 1 . The point symmetry of the central atom $\left(\mathrm{M}^{\mathrm{IV}}\right)$ 


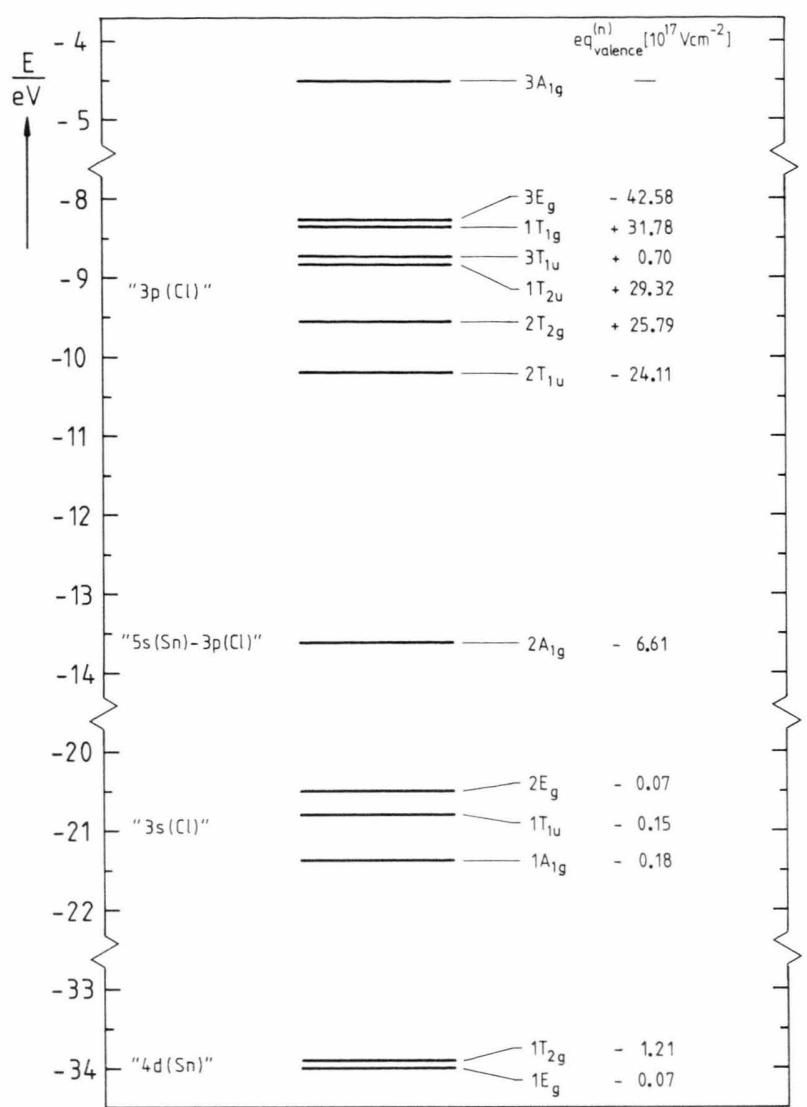

Fig. 2. Molecular energy levels of $\left[\mathrm{SnCl}_{6}\right]^{2-}$. Displayed are the levels formed by the $3 \mathrm{~s}$ and $3 \mathrm{p}$ electrons of $\mathrm{Cl}$ and the $4 \mathrm{~d}$ and $5 \mathrm{~s}$ electrons of $\mathrm{Sn}$. Furthermore, the contributions of these electrons to the electric field gradient $\left(e q_{\text {valence }}^{(\mathrm{n})}\right)$ are listed.

is $\mathrm{O}_{\mathrm{h}}$. In case of distorted octahedra we have assumed $\mathrm{D}_{4 \mathrm{~h}}$-symmetry. Experimentally, $\mathrm{D}_{3 \mathrm{~h}}$-symmetry or even lower symmetries are observed, too. In case of the $\left[\mathrm{SnCl}_{6}\right]$ octahedron, there are 58 valence electrons in the complex (including the outermost d-shell of $\mathrm{Sn}^{\mathrm{IV}}$ ). Two sets of radii of the muffin-tin spheres are chosen. Firstly the spheres do not overlap and furthermore for $\mathrm{Cl}^{-}$the fixed ionic radius of $\mathrm{R}\left(\mathrm{Cl}^{-}\right)=1.218 \AA$ is used. Secondly these radii are changed in such a way that the muffin-tin spheres possess an overlap of $5 \%$ in the radii. First the energy levels of the electronic valence states shall be considered. Figure 2 gives the term scheme deduced from the $\mathrm{X} \alpha$-calculation for $\left[\mathrm{SnCl}_{6}\right]^{2-}$. For comparison we have also performed a band structure calculation for $\mathrm{Cs}_{2} \mathrm{SnCl}_{6}$ using the augmented spherical wave (ASW) procedure [21]. The

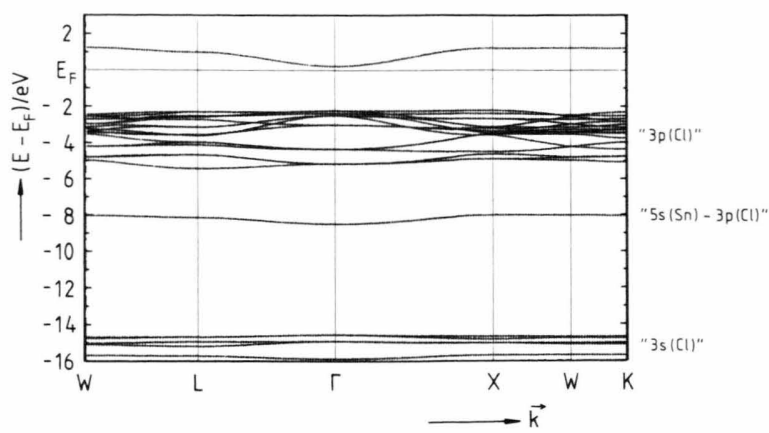

Fig. 3. Electron band structure (energy $E$ as a function of the wave vector $\boldsymbol{k}$ ) of the valence states of $\mathrm{Cs}_{2} \mathrm{SnCl}_{6}$, calculated by the ASW procedure. The electron level above $E_{\mathrm{F}}$ is unoccupied.

energy as a function of the wave vector $\boldsymbol{k}$ for various directions in $\boldsymbol{k}$-space is shown in Figure 3. One sees that the bands show only a small dispersion and the qualitative agreement of the position of the energy levels for both procedures is good. Therefore we think that the cluster calculation simulates the occupied electronic states of the crystal quite reasonably.

The MO character of the levels can be deduced from the partial charges $Q_{l}^{(\mathrm{n})}(i)$ given in Table 2. $Q_{l}^{(\mathrm{n})}(i)$ are the charges inside the muffin-tin spheres $i$ of the electron state $n$ associated with the angular momentum $l$. From the charges given in Table 2 one sees that the lowest two levels in Fig. 2 correspond to the $4 \mathrm{~d}$ states of Sn (labelled " $4 \mathrm{~d}(\mathrm{Sn})$ )" in Figure 2). The next three levels are formed predominately by the $3 \mathrm{~s}$ electrons of chlorine (" $3 \mathrm{~s}(\mathrm{Cl})$ "). The other occupied levels are the $3 \mathrm{p}$ states of chlorine, one of these states $\left(2 \mathrm{~A}_{1 \mathrm{~g}}\right)$ is distinctly lower in energy than the others. This state is mainly a hybrid state of the $3 \mathrm{p}$ chlorine and the $5 \mathrm{~s}$ tin states (" $5 \mathrm{~s}(\mathrm{Sn})-3 \mathrm{p}(\mathrm{Cl})$ "). The uppermost valence states are predominately $3 \mathrm{p}$ states of $\mathrm{Cl}($ " $3 \mathrm{p}(\mathrm{Cl})$ "). The overall charge distribution can be roughly described by $\mathrm{Sn}^{1.36+}\left(\mathrm{Cl}^{0.56-}\right)_{6}$. The term diagrams of all compounds with $\mathrm{O}_{\mathrm{h}}$ symmetry considered here are very similar to the one shown in Figure 2. The state energies of all compounds studied here are of course a little bit different, but the arrangement of the levels is very similar.

Furthermore, the distribution in " $3 \mathrm{~s}(\mathrm{Cl})-$ ", "3p(Cl)-", and a hybrid level containing the highest s-level of the tetravalent metal ion $\mathrm{M}^{\mathrm{IV}}$ and $\mathrm{a}$ $3 \mathrm{p}(\mathrm{Cl})$-state is always found. For tin and tellurium the highest s-level is the $5 \mathrm{~s}$-state, whereas for lead and titanium it is the $6 \mathrm{~s}$ - and the $4 \mathrm{~s}$-state, respectively. The 
Table 2. Partial charges $Q^{(\mathrm{n})}(i)$ of the electronic valence states $\mathrm{n}$ inside the muffin-tin sphere, $i=\mathrm{Sn}, \mathrm{Cl}$. $Q^{(\mathrm{n})}(i)$ is also seperated into the $l$ components $(\mathrm{s}, \mathrm{p}, \mathrm{d}) Q_{l}^{(\mathrm{n})}(i)$.

\begin{tabular}{|c|c|c|c|c|c|c|c|c|}
\hline \multirow{2}{*}{$\begin{array}{l}\text { State } \\
\mathrm{n}\end{array}$} & \multicolumn{4}{|c|}{$i=\mathrm{Sn}$} & \multicolumn{4}{|c|}{$i=\mathrm{Cl}$} \\
\hline & $Q_{\mathrm{s}}^{(\mathrm{n})}$ & $Q_{\mathrm{p}}^{(\mathrm{n})}$ & $Q_{\mathrm{d}}^{(\mathrm{n})}$ & $Q^{(\mathrm{n})}$ & $Q_{\mathrm{s}}^{(\mathrm{n})}$ & $Q_{\mathrm{p}}^{(\mathrm{n})}$ & $Q_{\mathrm{d}}^{(\mathrm{n})}$ & $Q^{(\mathrm{n})}$ \\
\hline $3 \mathrm{E}_{\mathrm{g}}$ & 0.000 & 0.000 & 0.034 & 0.034 & 0.000 & 0.915 & 0.000 & 0.915 \\
\hline $1 \mathrm{~T}_{1 \mathrm{~g}}^{\mathrm{g}}$ & 0.000 & 0.000 & 0.000 & 0.000 & 0.000 & 0.980 & 0.001 & 0.981 \\
\hline $3 \mathrm{~T}_{1 \mathrm{u}}^{\mathrm{Ig}}$ & 0.000 & 0.024 & 0.000 & 0.024 & 0.001 & 0.940 & 0.002 & 0.943 \\
\hline $1 T_{2 u}$ & 0.000 & 0.000 & 0.004 & 0.004 & 0.000 & 0.978 & 0.001 & 0.979 \\
\hline $2 \mathrm{~T}_{2 \mathrm{~g}}$ & 0.000 & 0.000 & 0.010 & 0.010 & 0.000 & 0.968 & 0.002 & 0.970 \\
\hline $2 \mathrm{~T}_{1 \mathrm{u}}$ & 0.000 & 0.143 & 0.000 & 0.143 & 0.009 & 0.813 & 0.008 & 0.830 \\
\hline $2 \mathrm{~A}_{1 \mathrm{~g}}$ & 0.487 & 0.000 & 0.000 & 0.487 & 0.072 & 0.396 & 0.024 & 0.492 \\
\hline $2 \mathrm{E}_{\mathrm{g}}$ & 0.000 & 0.000 & 0.009 & 0.009 & 0.980 & 0.000 & 0.000 & 0.980 \\
\hline $1 \mathrm{~T}_{1 \mathrm{u}}$ & 0.000 & 0.016 & 0.000 & 0.016 & 0.972 & 0.001 & 0.000 & 0.973 \\
\hline $\begin{array}{l}\mathrm{CA}_{1 \mathrm{~g}} \\
1 \mathrm{~T}_{2}\end{array}$ & 0.000 & 0.000 & $\begin{array}{l}0.000 \\
0.999\end{array}$ & $\begin{array}{l}0.0 / 1 \\
0.999\end{array}$ & $\begin{array}{l}0.911 \\
0.000\end{array}$ & 0.009 & 0.001 & $\begin{array}{l}0.921 \\
0.001\end{array}$ \\
\hline $1 \mathrm{E}_{\mathrm{g}}$ & 0.000 & 0.000 & 0.989 & 0.989 & 0.004 & 0.004 & 0.003 & 0.011 \\
\hline
\end{tabular}

Table 3. Contributions to the electric field gradient $e q$ (in $10^{17} \mathrm{~V} \mathrm{~cm}^{-2}$ ) and partial charges of the atoms calculated for several $\left[\mathrm{M}^{\mathrm{IV}} \mathrm{Cl}_{6}\right]$ complexes. For the definition of the contributions $e q_{i}$ see (4)-(9) in the text.

\begin{tabular}{|c|c|c|c|c|c|c|c|c|c|c|c|c|}
\hline $\begin{array}{l}\mathrm{EFG} \\
{\left[10^{17} \mathrm{~V} \mathrm{~cm}^{-2}\right]}\end{array}$ & \multicolumn{2}{|l|}{$\mathrm{Cs}_{2} \mathrm{GeCl}_{6}$} & \multicolumn{2}{|l|}{$\mathrm{K}_{2} \mathrm{SnCl}_{6}$} & \multicolumn{2}{|l|}{$\mathrm{Cs}_{2} \mathrm{SnCl}_{6}$} & \multicolumn{2}{|l|}{$\mathrm{Cs}_{2} \mathrm{PbCl}_{6}$} & \multicolumn{2}{|l|}{$\mathrm{Cs}_{2} \mathrm{TeCl}_{6}$} & \multicolumn{2}{|l|}{$\mathrm{Rb}_{2} \mathrm{TiCl}_{6}$} \\
\hline Overlap ${ }^{a}$ & $0 \%$ & $5 \%$ & $0 \%$ & $5 \%$ & $0 \%$ & $5 \%$ & $0 \%$ & $5 \%$ & $0 \%$ & $5 \%$ & $0 \%$ & $5 \%$ \\
\hline$e q_{\text {local }}$ & 22.16 & 23.53 & 15.13 & 17.33 & 15.13 & 17.33 & 16.09 & 17.87 & 18.12 & 19.29 & 6.72 & 8.10 \\
\hline$e q_{\text {distant }}$ & 0.16 & 0.13 & 0.23 & 0.20 & 0.23 & 0.20 & 0.17 & 0.13 & 0.15 & 0.13 & 0.22 & 0.18 \\
\hline$e q_{\text {lattice }}$ & -0.0964 & -0.0964 & -0.1161 & -0.1148 & -0.0993 & -0.0984 & -0.1024 & -0.1006 & -0.0965 & -0.0959 & -0.1107 & -0.1095 \\
\hline$\left(1-\gamma_{\infty}\right) \cdot e q_{\text {lattice }}$ & -4.15 & -4.15 & -4.99 & -4.94 & -4.27 & -4.23 & -4.40 & -4.33 & -4.15 & -4.12 & -4.76 & -4.71 \\
\hline$e q_{\text {total }}$ & 18.17 & 19.51 & 10.37 & 12.59 & 11.09 & 13.30 & 11.86 & 13.67 & 14.12 & 15.30 & 2.18 & 3.57 \\
\hline$e q_{\exp }$ & \multicolumn{2}{|c|}{19.97} & \multicolumn{2}{|c|}{15.63} & \multicolumn{2}{|c|}{16.66} & \multicolumn{2}{|c|}{18.38} & \multicolumn{2}{|c|}{16.19} & \multicolumn{2}{|c|}{8.21} \\
\hline Charge $Z_{M^{1 V}}^{\prime}$ & +0.76 & +0.76 & +1.36 & +1.24 & +1.36 & +1.24 & +1.24 & +1.06 & +1.00 & +0.94 & +1.12 & +1.00 \\
\hline Charge $\mathrm{Z}_{\mathrm{Cl}}^{\prime}$ & -0.46 & -0.46 & -0.56 & -0.54 & -0.56 & -0.54 & -0.54 & -0.51 & -0.50 & -0.49 & -0.52 & -0.50 \\
\hline
\end{tabular}

a Overlap of the muffin-tin radii, see Table 1. ' ${ }^{\mathrm{b}}$ Ref. [1, 22-24].

valence states with the lowest energy are the $4 \mathrm{~d}$-states in case of $\mathrm{Sn}$ and $\mathrm{Te}$, and the $5 \mathrm{~d}$-states for $\mathrm{Pb}$. Titanium has no occupied d-states.

Comparing $\mathrm{Sn}, \mathrm{Pb}, \mathrm{Ti}$, and $\mathrm{Te}$ one finds that $\mathrm{Te}$ has two more valence electrons than the other metals. In the $\left[\mathrm{TeCl}_{6}\right]^{2-}$ octahedron these electrons occupy the $3 \mathrm{~A}_{1 \mathrm{~g}}$-level, which is unoccupied in case of the other hexachlorometallates.

Next we consider the EFG of the complex at the chlorine site $e q_{\text {complex }}$. In Fig. 2 the contributions of the electronic valence states $\mathrm{n}$ to $e q_{\text {complex }}, e q_{\mathrm{valence}}^{(\mathrm{n})}$, are given. Summing up the contributions given in Fig. 2 one gets $e q_{\text {valence }}=\sum e q_{\text {valence }}^{(\mathrm{n})}=11.83 \cdot 10^{17} \mathrm{~V} \mathrm{~cm}^{-2}$. That means that the sum is in the same order of magnitude as the contributions of the various electronic states $\left(e q_{\text {valence }}\right.$ differs slightly from $e q_{\text {local }}$ defined in (4) as $e q_{\text {valence }}$ is equal to an integral over $\Omega_{\mathrm{C}}$ instead of $\Omega_{\mathrm{Cl}}$ ).

In Table 3 the different contributions to the EFG defined in Section III are summarized for the hexa- chlorometallates studied here and the resulting charges of the atoms are listed. For comparison the experimental data for the EFG are given, too.

Under the assumption of $\eta=0$ the electric field gradient $e q$ can be deduced from the experimental ${ }^{35} \mathrm{ClNQR}$ frequency $v\left({ }^{35} \mathrm{Cl}\right)$ by the equation

$$
\begin{aligned}
e q\left[\mathrm{~V} \mathrm{~cm}^{-2}\right] & =2 \cdot h v / e Q \\
& =1.038 \cdot 10^{17} \cdot v\left({ }^{35} \mathrm{Cl}\right)[\mathrm{MHz}],
\end{aligned}
$$

where $e$ is the unit charge $\left(e=1.6022 \cdot 10^{-19} \mathrm{As}\right), Q$ is the nuclear quadrupole moment of ${ }^{35} \mathrm{Cl}(Q=$ $-0.0797 \cdot 10^{-24} \mathrm{~cm}^{+2}$ ) and $h$ is the Planck constant $\left(h=6.626 \cdot 10^{-34} \mathrm{Js}\right)$.

The last two rows of Table 3 give the partial charges used as the point charges for the lattice sum calculations.

One sees from Table 3 that the main contribution to the EFG is $e q_{\text {local }}$. The contribution $e q_{\text {lattice }}$ is much smaller and is opposite in sign. However, including the shielding effect the lattice contribution is not negli- 
Table 4. Comparison of the electric field gradient (EFG) in the regular $\left[\mathrm{SnCl}_{6}\right]^{-2}$ octahedron $e q_{0}$ (symmetry $\mathrm{O}_{\mathrm{h}}$ ) and the distorted octahedron $e q_{1}$ and $e q_{2}$ (symmetry $\mathrm{D}_{4 \mathrm{~h}}$ ) using nonoverlapping spheres. $e q_{1}$ is the EFG at $\mathrm{Cl} 1\left(d_{\mathrm{Sn}-\mathrm{C} 11}=2.42 \AA\right)$ and $e q_{2}$ is the EFG at Cl2 $\left(d_{\mathrm{Sn}-\mathrm{Cl} 2}=2.46 \AA\right)$; see also Table 1 . Besides $e q_{\text {local }}, e q_{\text {distant }}$, and $e q_{\text {lattice }}$ (see Eqs. 4-9) the contribution of the valence states $e q_{\text {valence }}$ are given too, $e q_{\text {valence }}$ is seperated into the contributions of the " $3 \mathrm{p}(\mathrm{Cl})$ " to " $4 \mathrm{~d}(\mathrm{Sn})$ " electrons, see Figure 2. $\eta$ is the asymmetry parameter. The $e q_{i}$ are given in $10^{13} \mathrm{~V} \mathrm{~cm}^{-2}$.

\begin{tabular}{llrrr}
\hline & & $e q_{0}$ & \multicolumn{1}{c}{$e q_{1}$} & \multicolumn{1}{c}{$e q_{2}$} \\
\hline $2 \mathrm{~T}_{1 \mathrm{u}}-3 \mathrm{E}_{\mathrm{g}}$ & "3p $(\mathrm{Cl}) "$ & 20.90 & 21.97 & 19.19 \\
$2 \mathrm{~A}_{1 \mathrm{~g}}-2 \mathrm{E}_{\mathrm{g}}$ & "5s $(\mathrm{Sn})-3 \mathrm{~s}(\mathrm{Cl}) "$ & -6.61 & -6.86 & -5.63 \\
$\left.1 \mathrm{~A}_{1 \mathrm{~g}}-2 \mathrm{Cl}\right) "$ & -0.40 & -0.37 & -0.35 \\
$1 \mathrm{E}_{\mathrm{g}}-1 \mathrm{~T}_{2 \mathrm{~g}}$ & "4d $(\mathrm{Sn}) "$ & -1.28 & -2.07 & -1.97 \\
$e q_{\text {valence }}$ & 12.61 & 12.67 & 11.24 \\
$e q_{\text {local }}$ & 15.13 & 15.95 & 14.41 \\
$e q_{\text {distant }}$ & 0.23 & 0.24 & 0.23 \\
$e q_{\text {lattice }} \cdot\left(1-\gamma_{\infty}\right)$ & -4.27 & -4.31 & -4.32 \\
$e q_{\text {total }}$ & 11.09 & 11.88 & 10.32 \\
$\eta$ & 0.000 & 0.009 & 0.000 \\
\hline
\end{tabular}

gible. Furthermore the trend in the EFG going from potassium hexachlorostannate to cesium hexachlorostannate is mainly caused by the change of the lattice constant. Changing, on the other hand, the central atom of the complex the change in the EFG is primarily due to the change in $e q_{\text {local }}$.

To study the influence of the size of the chosen atomic spheres on the calculated EFG we have also performed calculations using overlapping spheres. The radii of the muffin-tin spheres have been enhanced by $5 \%$, see Table 1 . The calculated EFG using overlapping spheres is also listed in Table 3. One sees that the EFG changes distinctly by going from nonoverlapping spheres to overlapping ones. However, the results deduced from the overlapping spheres model show the same trends as the ones using nonoverlapping spheres.

Besides the study of a regular octahedron we have performed cluster calculations for a distorted octahedron (symmetry $\mathrm{D}_{4 \mathrm{~h}}$ ). Table 4 shows the results of the EFG for the distorted $\left(e q_{1}\right.$ and $\left.e q_{2}\right)$ and the regular $\left[\mathrm{SnCl}_{6}\right]^{2-}$ octahedra $\left(e q_{0}\right)$. For the distorted octahedron the $\mathrm{M}^{\mathrm{VI}}-\mathrm{Cl}$ distance of two trans chlorine atoms to the central atom is increased from $2.42 \AA$ to $2.46 \AA$. As the main differences in $e q_{0}, e q_{1}$ and $e q_{2}$ result from the contribution $e q_{\text {local }}$, the $e q$ values for the electronic p-states for $\mathrm{Cl}$ (the levels $3 \mathrm{E}_{\mathrm{g}}$ to $2 \mathrm{~T}_{1 \mathrm{u}}$ in Fig. 1), the $\mathrm{s}(\mathrm{Sn})-\mathrm{p}(\mathrm{Cl})$-state $(\mathrm{A} 1 \mathrm{~g})$, the $\mathrm{s}(\mathrm{Cl})$-states $\left(2 \mathrm{E}_{\mathrm{g}}\right.$ to $\left.\mathrm{A}_{1 \mathrm{~g}}\right)$, and the $\mathrm{d}(\mathrm{Sn})$-states $\left(1 \mathrm{~T}_{2 \mathrm{~g}}\right.$ and $\left.1 \mathrm{E}_{\mathrm{g}}\right)$ are given seperately.
Comparing the results for the distorted and the undistorted systems one sees that the NQR frequencies should split into a lower one for the $\mathrm{Cl}$ atom with the larger $\mathrm{Sn}-\mathrm{Cl}$ distance and a larger one for the other chlorine atoms. This trend is indeed observed experimentally. One finds from Table 4 that the change of the EFG going from the regular to the distorted system is predominately due to the change in the contribution of the uppermost valence states (“3p $(\mathrm{Cl})$ "-valence states in Figure 2).

\section{Discussion}

Before discussing the various contributions to the EFG in the hexachlorometallates, the total calculated EFG shall be compared with the data found experimentally.

Comparing the experimental and the theoretical values of the EFG given in Table 3 one recognizes that $E F G_{\text {theo. }}$ is always smaller than $E_{F} G_{\text {exp. }}$. We think that this is mainly caused by $\mathrm{EFG}_{\text {complex }}$, which might be too small in the present approach for the following reason: In the $\mathrm{X} \alpha$-model the electron potentials around the nuclei are approximated by their spherical averages; see above, Section II. Therefore the asymmetry of the charge density, which causes the electric field gradient in the electronic charge is only considered after the last cycle of the SCF procedure. This means that part of the non-sphericity of the potential due to the electronic charge inside the muffin-tin spheres considered is not taken into account and that the covalent contribution to the EFG is probably underestimated within this approach.

Besides the errors in calculating $\mathrm{EFG}_{\text {complex }}$ the shortcomings of the point charge model must be considered. The main source of error is the use of the chosen antishielding factor. The value used is deduced for the charge distribution of a $\mathrm{Cl}^{-}$ion. As $\gamma_{\infty}$ is decreasing with decreasing effective charge of the atom, the $\gamma_{\infty}$ value for the chlorine in the complex should be smaller than the one used here. Interpolating $\gamma_{\infty}\left(\mathrm{Cl}^{-}\right)=-42$ to an effective $\gamma_{\infty}\left(\mathrm{Cl}^{-0.56}\right)$ gives the value of $\gamma_{\infty}=-39$. Therefore we assume that the calculated values of $\mathrm{EFG}_{\text {lattice }}$ might overestimate the absolute value of this contribution. Summarizing the comparison between $\mathrm{EFG}_{\text {theo. }}$ and $E F G_{\text {exp. }}$ we think that the values for $E F G_{\text {complex }}$ and $\mathrm{EFG}_{\text {lattice }}$ are smaller than the "true" values for these 
contributions to the EFG. However, we think that a more sophisticated calculation would give the same trends in the various contributions to the EFG as the ones found here.

Next we turn to the discussion of the various contributions to $\mathrm{EFG}_{\text {local }}$. EFG $\mathrm{F}_{\text {local }}$ is mainly caused by the $3 \mathrm{p}$ wave functions of $\mathrm{Cl}$.

In a simple approximation this contribution can be written as [25]

$$
e q_{\text {local }}^{(\mathrm{n})} \approx-4 / 5 e\left\langle r^{-3}\right\rangle\left(Q_{\mathrm{p}_{z^{\prime}}}^{(\mathrm{n})}-Q_{\mathrm{p}_{x^{\prime}}}^{(\mathrm{n})}\right),
$$

where $\mathrm{n}$ is the electronic state considered, $\left\langle r^{-3}\right\rangle$ is the radial expectation value of $r^{-3},\left(x^{\prime}, y^{\prime}, z^{\prime}\right)$ is the principal axis system, and where it is assumed that $Q_{\mathrm{p}_{x^{\prime}}}^{(\mathrm{n})}=Q_{\mathrm{p}_{y^{\prime}}}^{(\mathrm{n})}(\eta=0)$. Depending on the occupation numbers of the $\mathrm{p}_{\mathrm{p}_{i}}$, orbitals $\left(x_{i}^{\prime}=x^{\prime}, y^{\prime}, z^{\prime}\right) e q^{(\mathrm{n})}$ can be positive or negative. The basis function of the representation $\mathrm{A}_{1 \mathrm{~g}}$ is the $\mathrm{p}_{z}$-orbital, and therefore $Q_{\mathrm{p}_{x^{\prime}}}^{\left(\mathrm{A}_{1 \mathrm{~g}}\right)}=0$ and $e q_{\text {local }}^{\left(\mathbf{A}_{1}\right)}$ is always negative. For the two or three dimensional representations, however, the sign of $e q_{\text {local }}^{(\mathrm{n})}$ can not be predicted in advance, as the $\mathrm{p}_{x}$, as well as the $\mathrm{p}_{z}$, orbitals belong to the basis function system. Depending on the dominance of $Q_{\mathrm{p}_{x}}$ or $Q_{\mathrm{p}_{z}}$, respectively, $e q_{\text {local }}^{\text {(n) }}$ can be positive or negative.

According to the partial cancellation of the terms $e q_{\text {local }}^{(\mathrm{n})}$ it follows that the total contribution $e q_{\text {local }}=\sum e q_{\text {local }}^{(\mathrm{n})}$ is in the same order of magnitude as the $e q_{\text {local }}^{(\mathrm{n})}$ itself. Because of this cancellation it is rather complicated to predict a general trend in the EFG in the hexachlorometallates based on a simple effect as the occupation of one single electronic valence state. Discussing $e q_{\text {local }}$ in the series of compounds with different IVa elements $(\mathrm{Ge}, \mathrm{Sn}, \mathrm{Pb})$ as central atom one finds that the EFG is decreasing going from the Ge to the Sn compound, and increasing going from the Sn to the $\mathrm{Pb}$ compound. It is interesting to note that the decrease in the EFG is accomplished by an increase of the negative charge at the $\mathrm{Cl}$-atom (see last row in Table 3). This behaviour can be explained by the simple picture that an additional negative charge of the partial charged $\mathrm{Cl}$-atom increases the occupation number of the $\mathrm{p}_{z}$ orbital whereas the "lonepair" $\mathrm{p}_{x}, \mathrm{p}_{y}$ levels are fully occupied. As can be seen from (10), for

[1] D. Nakamura, Bull. Chem. Soc. Japan 36, 1162 (1963).

[2] L. Ramakrishnan, S. Soundararajan, V.S. S. Sastry, and J. Ramakrishna, Coord. Chem. Rev. 22, 123 (1977).

[3] Al. Weiss, Top. Curr. Chem. 30, 1 (1972).

[4] T. P. Das and E. L. Hahn, Nuclear Quadrupole Resonance Spectroscopy, Academic Press, New York 1958. fixed $Q_{\mathrm{p}_{x}}$ and increasing $Q_{\mathrm{p}_{z}}$ the $e q_{\text {local }}$ value should decrease.

Next the lattice contribution $e q_{\text {lattice }}$ shall be considered. Due to the $1 / r^{3}$ dependence of the EFG (see (4)) $\left|E F G_{\text {lattice }}\right|$ decreases with increasing lattice constant of the compound, and as the size of the $\mathrm{M}^{\mathrm{I}}$ element increases with increasing atomic number one finds that $\left|\mathrm{EFG}_{\text {lattice }}\right|$ decreases going from the $\mathrm{K}$ to the Cs compound. Taking the shielding effect into account one finds that this change in $\mathrm{EFG}_{\text {lattice }}$ seems to be responsible for the change in the EFG for compounds which possess the same central atom $\left(\mathrm{M}^{\mathrm{IV}}\right)$ but different cations.

Finally the theoretical results for the EFG in a distorted octahedron shall be compared with the EFG of the regular octahedron. One finds from Table 4 that the EFG for the shorter distance $\mathrm{Sn}-\mathrm{Cl}, e q_{1}$, is smaller than the one for the longer $\mathrm{Sn}-\mathrm{Cl}$ distance, $e q_{2}$, and that $e q_{1}<e q_{0}<e q_{2}$, where $e q_{0}$ is the EFG at the chlorine site for the undistorted system. The differences in $e q_{1}, e q_{2}$ and $e q_{0}$ are mainly caused by differences in the occupation numbers of the valence " $3 \mathrm{p}(\mathrm{Cl})$ " state, see first row of Table 4 . Within the calculation reported here the s-amplitudes of the chlorine atoms are nearly the same for the three different $\mathrm{Cl}$-atoms given in Table $4\left(\mathrm{Cl}_{0}, \mathrm{Cl}_{1}, \mathrm{Cl}_{2}\right)$ and therefore the change in the EFG cannot be explained by a change in the sp-hybridization. Furthermore, the change in the EFG due to the change in the distance to the neighbours $\left(1 / r^{3}\right.$-terms) is distinctly smaller than the change in the covalent terms mentioned above. Moreover we want to point out that the charge at the chlorine atom is larger for the $\mathrm{Cl}$ closer to the central atom than the one for the chlorine atom for which the $\mathrm{Sn}-\mathrm{Cl}$ distance is larger. Here the simple assumption that the EFG should be smaller for the more negatively charged chlorine atom fails.

\section{Acknowledgement}

We grateful thank the 'Deutsche Forschungsgemeinschaft' and the 'Fonds der Chemischen Industrie' for support of this work.

[5] T. B. Brill, Z. Z. Hugus, and A. F. Schreiner, J. Phys. Chem. 74, 2999 (1970).

[6] M. Cook and D. A. Case, XASW-Program, Harvard University, Cambridge (1982), QCPE-No. 465, available from QCPE Indiana University, Dept. of Chemistry.

[7] W. Kohn and L. J. Sham, Phys. Rev. 140 A, 1133 (1965). 
[8] J. C. Slater, The Self-consistent Field for Molecules and Solids Vol. 4, Mc-Graw Hill, New York 1974.

[9] K. H. Johnson, Adv. Quantum Chem. 7, 143 (1973).

[10] T. P. Das and R. Bersohn, Phys. Rev. 102, 733 (1956).

[11] P. C. Schmidt, H. M. Maurer, and Al. Weiss, J. Mol. Struct. 41, 111 (1977).

[12] D. Borchers and Al. Weiss, Ber. Bunsenges. Phys. Chem. 90, 716 (1986); 91, 1182 (1987); Z. Naturforsch. 42 A, 739 (1987).

[13] K. Schwarz, Phys. Rev. B 22, 4167 (1980).

[14] R. E. Watson, Phys. Rev. 111, 1108 (1958).

[15] E. Paschalis and Al. Weiss, Theor. Chim. Acta 13, 381 (1969).

[16] R. M. Sternheimer, Z. Naturforsch. 41 A, 24 (1986).

[17] P. C. Schmidt, K. D. Sen, T. P. Das, and Al. Weiss, Phys. Rev. B 22, 4167 (1980).
[18] A. W. Laubengayer, A. W. Billings, and A. E. Newkirk, J. Amer. Chem. 62, 546 (1980).

[19] T. B. Brill, R. C. Gearhart, and W. A. Welsh, J. Magn. Res. 13, 27 (1974).

[20] G. Engel, Z. Krist. 90, 341 (1935).

[21] A. R. Williams, J. Kübler, and C. D. Gelatt, Phys. Rev. B 19, 6094 (1979).

[22] R. Kadel, Diplomarbeit, Darmstadt 1974.

[23] T. L. Brown and L. G. Kent, J. Phys. Chem. 74, 3572 (1970).

[24] T. B. Brill and W. A. Welsh, J. Chem. Soc. Dalton 1973, 357.

[25] P. C. Schmidt, Al. Weiss, S. Cabus, and J. Kübler, Z. Naturforsch. 42a, 1321 (1987). 